\title{
Androgenetic alopecia: a review
}

\author{
Francesca Lolli ${ }^{1}$ - Francesco Pallotti ${ }^{1}$ - Alfredo Rossi ${ }^{2}$ - Maria C. Fortuna ${ }^{2}$. \\ Gemma Caro $^{2} \cdot$ Andrea Lenzi $^{1} \cdot$ Andrea Sansone $^{1} \cdot$ Francesco Lombardo $^{1}$
}

Received: 21 December 2016 / Accepted: 25 February 2017 / Published online: 28 March 2017

(C) Springer Science+Business Media New York 2017

\begin{abstract}
Purpose Androgenetic alopecia, commonly known as male pattern baldness, is the most common type of progressive hair loss disorder in men. The aim of this paper is to review recent advances in understanding the pathophysiology and molecular mechanism of androgenetic alopecia.

Methods Using the PubMed database, we conducted a systematic review of the literature, selecting studies published from 1916 to 2016.

Results The occurrence and development of androgenetic alopecia depends on the interaction of endocrine factors and genetic predisposition. Androgenetic alopecia is characterized by progressive hair follicular miniaturization, caused by the actions of androgens on the epithelial cells of genetically susceptible hair follicles in androgen-dependent areas. Although the exact pathogenesis of androgenetic alopecia remains to be clarified, research has shown that it is a polygenetic condition. Numerous studies have unequivocally identified two major genetic risk loci for androgenetic alopecia, on the X-chromosome AR/EDA2R locus and the chromosome 20p11 locus.

Conclusions Candidate gene and genome-wide association studies have reported that single-nucleotide polymorphisms at different genomic loci are associated with androgenetic alopecia development. A number of genes determine the predisposition for androgenetic alopecia in a polygenic
\end{abstract}

Francesco Lombardo

francesco.lombardo@uniroma1.it

1 Department of Experimental Medicine, University of Rome "La Sapienza", Rome, Italy

2 Department of Internal Medicine and Medical Specialties, University of Rome "La Sapienza", Rome, Italy fashion. However, further studies are needed before the specific genetic factors of this polygenic condition can be fully explained.

Keywords AGA - Male pattern baldness - AGA genetics · Androgen receptor $\cdot$ Androgen metabolism $\cdot$ Finasteride

\section{Introduction}

Androgenetic alopecia (AGA), also known as androgenic alopecia or male pattern baldness, is the most common type of progressive hair loss. AGA is a polygenetic condition with varying severity, age of onset, and scalp location of hair loss. In men, hair loss typically involves the temporal and vertex region while sparing the occipital region: the characteristic "horseshoe" pattern.

Incidence and prevalence of AGA depend on age and race. Based on the little prevalence data available, we know that up $30 \%$ of white men will have AGA by the age of 30 years, up to $50 \%$ by 50 years, and $80 \%$ by 70 years [1-3]. Chinese, Japanese, and African American people are less affected than Caucasians [4].

AGA features a progressive miniaturization of the hair follicle leading to vellus transformation of terminal hair. This results from an alteration in hair cycle dynamics: anagen phase duration gradually decreases and that of the telogen phase increases. As the anagen phase duration determines hair length, the new anagen hair becomes shorter, eventually leading to bald appearance $[5,6]$.

In 1951, Hamilton referred to the mutual interplay of androgens, genetic and age factors in the origin of AGA [1]. 
Hamilton's observations on hypogonadal men established that androgens were prerequisites for the development of common baldness: men castrated before puberty did not develop AGA, and AGA could be triggered in castrated men by injecting testosterone.

Although these changes are driven by androgens, most of the molecular mechanisms are unknown, limiting available treatments.

Predisposition to AGA predominantly depends on genetics. Twin studies show strong concordance rates of between 80 and $90 \%$ for monozygotic twins. Family analyses show a significantly increased risk for AGA in men with a bald father [7], while the risk is significantly decreased in men with a non-balding father. However, the risk of developing AGA also increases with a positive family history on the side of the mother, or of the maternal grandfather [7]. This transmission through many successive generations suggests the involvement of a single major gene.

In 1916, Osborn proposed that the pattern of AGA may be consistent with an autosomal dominant trait [8]. Kuster and Happle reviewed the genetics of AGA and concluded that Osborn's hypothesis had not been thoroughly tested and was thus of questionable validity [9]. In their analysis of five previous studies, they concluded that a polygenic mode of inheritance was more likely. The current scientific data support the thesis that AGA has a polygenic trait, but its pathophysiology and genetics are not fully understood. Significant associations have been reported with variant regions of the androgen receptor gene, located on the Xchromosome. AGA is most likely a multifactorial disorder caused by interactions among several genes and environmental factors [10]. We aim to review recent advances in the pathophysiology and molecular mechanism of AGA.

\section{Androgens and hair follicles}

Androgens affect several functions of the human skin, including sebaceous gland growth and differentiation, hair growth, the epidermal barrier, and wound healing, mainly through a multi-step intracellular signaling pathway [11]. Although human hair growth is also affected by thyroid hormones and glucocorticoid [12], androgens are the most important regulators: they can stimulate, leave unaltered or inhibit terminal hair growth, depending on the body site. Androgens can enlarge the hair follicles in androgendependent areas (beard, axillary, and pubic hair) but, paradoxically, in scalp follicles of susceptible men, they suppress hair growth and promote miniaturization of and shorter hair in the anagen stage, leading to common baldness. Since the follicles are exposed to the same circulating hormones, this paradox may be explained by gene expression response to androgens in different body areas [13].
Hair follicle biology over the last 20 years has established the fundamental role of the mesenchyme-derived dermal papilla in the maintenance of hair growth [14-16]. Dermal papilla cells (DPC) play an important role in the induction and maintenance of epithelial cell growth [17] and mediate the growth stimulating signals of androgens by releasing growth factors that act in a paracrine fashion on the other follicle cells [5]. More recently, the discovery of higher levels of androgen receptors in cultured DPCs from balding scalp hair follicles supported the hypothesis developed by Randall et al. that androgens act on epithelial cells of the hair follicle via the mesenchyme-derived dermal papilla, stimulating some hair follicles (e.g. beard) while inhibiting others, altering the production of regulatory factors [18].

This cross-talk between the dermal papilla and the hair follicle cells results from the secretion of numerous growth factors and/or extracellular matrix factors from the dermal papilla $[15,19]$. These growth factors have an autocrine effect on the dermal papilla itself and a paracrine effect on the hair follicle epithelial cells [20]. They include insulin like growth factor 1 (IGF-1), basic fibroblast growth factor, vascular endothelial growth factor, all of which stimulate hair growth, and cytokines such as transforming growth factor beta 1 (TGF- $\beta 1$ ), interleukin 1 alpha, and tumor necrosis factor alpha, with inhibitory and pro-apoptotic effects [15, 21-23].

The regional specificity of androgen action is also partly explained by in vitro experiments, where androgen stimulation of scalp DPCs induced TGF- $\beta 1$ production, while stimulation of beard DPCs induced IGF-1 as a second messenger [24]. Itami et al. observed that the synthetic androgen R1881 suppressed keratinocyte growth in the coculture of AR-overexpressing human DPCs from AGA and normal human keratinocytes, through androgeninducible TGF- $\beta 1[22,25]$. As TGF- $\beta 1$ is known to be a catagen inducer in hair cycling, it likely plays a role in the early catagen induction seen in AGA [26]. Furthermore, TGF- $\beta 2$, dickkopf1, and IL-6 have been identified as androgen-inducible negative mediators for AGA development in several in vitro experimental methods, thus providing new clues for clarifying the details of androgen action in AGA [27-29].

\section{Androgen metabolism}

Androgen action in hair follicles depends on their local bioavailability. Even if most men with AGA have normal circulating androgen levels, higher rates of testosterone and dihydrotestosterone (DHT) are produced locally [30]. The skin contains all the enzymatic equipment necessary for androgen metabolism and can be considered as a peripheral organ that locally synthesizes significant amounts of 
androgens with intracrine or paracrine actions [31]. The autonomous formation of androgens allows the human skin to adjust their levels according to local needs, and leads to different responses in the hair follicles [32].

Testosterone is the major circulating androgen [33]. It reaches the skin through capillary blood and it is converted to the more potent androgen DHT by $5 \alpha$-reductase $(5 \alpha \mathrm{R})$ in the cytoplasm. The weak androgens dehydroepiandrosterone (DHEA), dehydroepiandrosterone-sulfate (DHEA-S), and androstenedione are converted peripherally to the more potent androgens testosterone and DHT. In the skin, the conversion of DHEA, DHEA-S, and androstenedione into more potent androgens occurs in sebocytes, sweat glands, and DPCs [34]. In vitro studies have shown that specific enzyme expression and activity in cultured sebocytes and keratinocytes seem to allocate different duties to these cells [32]. Sebocytes maintain androgen homeostasis by testosterone synthesis from adrenal precursors and its inactivation, whereas keratinocytes are responsible for androgen degradation.

Androgen metabolism in the pilosebaceous units starts from the desulfation of DHEA-S to DHEA by steroid sulfate synthase in dermal papilla. Next, $3 \beta$-hydroxysteroid dehydrogenase $-\Delta 5 \rightarrow 4-$ isomerase (3 $\beta$-HSD) type 1 converts DHEA into androstenedione in the sebaceous glands [32] and dermal papilla [35]. Subsequently, androstenedione is converted into testosterone by $17 \beta$-hydroxysteroid dehydrogenase (17 $\beta$-HSD). Human sebaceous glands provide the cellular machinery needed to transcribe the genes for $17 \beta$-HSD types $1-5[32,36,37]$. $17 \beta$-HSD types 1,3 , and 5 support the formation of more active androgens, whereas the oxidative reaction induced by $17 \beta$-HSD types 2 and 4 deactivates them, indicating the possible role of sebaceous glands in the regulation of local androgen metabolism [32,37]. Alternatively, DHEA can be converted into androstenediol and testosterone by $17 \beta-H S D$ and $3 \beta-$ HSD respectively in the pilosebaceous unit [38].

Two $5 \alpha \mathrm{R}$ isoenzymes, type I ( $5 \alpha \mathrm{R} 1)$ and type II $(5 \alpha \mathrm{R} 2)$, irreversibly converts testosterone to DHT. $5 \alpha \mathrm{R} 1$ is detected in various androgen-independent organs such as the liver and brain, while $5 \alpha \mathrm{R} 2$ is predominantly observed in androgen-dependent organs such as the epididymis and prostate [39]. Inui et al. demonstrated that $5 \alpha \mathrm{R} 2$ expression is higher in DPCs from AGA and beard than in DPCs from other sites [40, 41]. Once formed, testosterone and DHT can be removed by conversion back to the weaker 17ketosteroids or can be metabolized via other enzymatic pathways into estrogens via cytochrome $\mathrm{P} 450$ aromatase. Aromatase activity is detectable in hair follicles [42], and its expression in the outer root sheath of terminal hair follicles in the anagen phase and in sebaceous glands [43] suggests a local balance system for androgens and estrogens and that hair follicles function as both targets and sources of estrogen [44].

Androgen concentration thus depends on the expression of each of the androgen-and estrogen-synthesizing enzymes in each cell type, with sebaceous and sweat glands being the major contributors [13, 32]. For example, changes in $5 \alpha \mathrm{R} 1$ and $5 \alpha \mathrm{R} 2$ expression and activity likely increase conversion of testosterone to DHT within the hair follicles [42]. Furthermore, androgen action is more complex than that of other steroids. Testosterone itself binds to receptors in some tissues, such as skeletal muscle, while in others, including secondary sexual tissues like the prostate, it is metabolized intracellularly by $5 \alpha \mathrm{R}$ enzymes to DHT, which binds more strongly to the AR to activate gene expression [45, 46].

All androgen-dependent follicles require androgen receptors (ARs) to respond, as proved by the absence of adult body hair in individuals with complete androgen insensitivity [47]. In contrast, the requirement for $5 \alpha \mathrm{R}$ varies with follicle site. Individuals with $5 \alpha \mathrm{R} 2$ deficiency only produce female patterns of pubic and axillary hair growth, despite masculinization of their body shape [48], suggesting that DHT is necessary for male specific follicles (beard, chest, and upper pubic diamond), while testosterone can stimulate the axilla and lower pubic triangle follicles characteristic of women. It is unclear why some follicles need DHT and others testosterone to stimulate the same cell types, although it is likely that the cells use different intracellular coactivator proteins. This appears to be another paradox of androgen action in human follicles, presumably due to differential gene expression within individual follicles.

\section{Androgen receptor (AR)}

The effects of androgens are mediated through the AR, a $110-\mathrm{kDa}$ ligand-inducible nuclear receptor that regulates the expression of target genes through binding to an androgen response element (ARE). Androgen binding changes the AR's protein conformation and leads to its dissociation from the heat shock proteins and its translocation from the cytoplasm to the nucleus, where it forms a homodimer and is recruited to the ARE in the promoter regions of androgenregulated genes to initiate the signaling cascade. However, it also undergoes intramolecular interactions that regulate its interactions with coactivators and influence its activity. In the skin, AR is found in epidermal and follicular keratinocytes, sebocytes, sweat gland cells, DPCs, dermal fibroblasts, endothelial cells, and genital melanocytes [32, 49, 50]. As in hair follicles it is localized not in epithelial cells but in the dermal papillae, the latter are a major target for androgen action [51, 52]. 
DPCs from balding scalp hair follicles contain significantly more androgen receptors than those derived from non-balding follicles [18]. A recent study demonstrated that DNA methylation of the AR promoter is increased in hair follicles from the occipital scalp compared with those from vertex AGA scalp [53]. Increased AR methylation, potentially resulting in reduced $\mathrm{AR}$ expression, may protect occipital hairs from miniaturization and hair loss.

Tissue-specific, distinct AR-associated coregulators might explain the regional difference in hair follicle growth in response to androgen stimulation. Hic-5/ARA55, a TGF$\beta 1$-inducible AR co-activator, is highly expressed in DPCs from androgen-sensitive sites such as AGA and beard, suggesting that Hic-5/ARA55 can enhance androgen sensitivity in DPCs [54, 55]. Hic-5/ARA55 acts as a scaffold protein, which recruits or stabilizes chromatin modifying coactivator complexes to target promoters. Hic-5/ARA55 levels were found to correlate with previously reported AR levels in DPCs from various sites $[18,20]$. Together, these findings suggest that the sensitivity of hair follicles to androgen is regulated through pre-receptor $5 \alpha \mathrm{R}[56,57]$, ARs and post-receptor androgen co-activators [55]. On the other hand, Lee et al. demonstrated a reduced ARA70b/ ELE1b expression in dermal papilla and hair bulbs from balding hairs. As ARA70b/ELE1b promotes cell growth, it is likely that this decrease contributes to the retardation of hair follicle growth and eventually leads to hair follicle miniaturization [58].

\section{Genetics and pathogenesis of AGA}

It has been established that AGA inheritance follows a polygenic model, given its high prevalence and the wide range of phenotypes.

As the androgen dependence of AGA is well established, early studies focused on functional variants in or around AR and on the two triplet-repeat polymorphisms of the transactivating domain: the polyglutamine (CAG) repeat lying proximal and the polyglycine (GGN) repeat lying distal to rs6152. In 1998, Sawaya et al. found that men with AGA had shorter $\mathrm{CAG}$ repeats than did controls, and suggested that $\mathrm{CAG}$ repeat length in AR may affect androgenmediated gene expression in hair follicles and sebaceous glands [59]. In another study, the shorter polyglycine repeat (GGN-23) was highly associated, suggesting that GGN-23 was closer to the AGA mutation or was itself the AGAsusceptibility allele [60]. However, neither the CAG nor GGN repeat polymorphisms appeared to be independently responsible for the association with AGA [61].

Different AR polymorphism and AR restriction sites were also investigated [62-67]. The StuI polymorphism was linearly related to AR activity and associated with AGA risk. The ubiquity of the AR gene StuI restriction site and the higher incidence of shorter triplet repeat haplotypes in bald men suggest that these markers are very close to a functional variant that is a necessary component of the polygenic determination of AGA. The AR-E211 A allele was associated with a lower risk of alopecia, while the EDA2R gene variation causes susceptibility to AGA [64].

Given the major role of the potent androgens testosterone and DHT in hair follicle miniaturization, the $5 \alpha \mathrm{R}$ enzyme was investigated in the AGA pathogenesis. However, no evidence was found that the gene for either of the two isoforms of the steroid $5 \alpha \mathrm{R}$ enzyme (SRD5A1 and SRD5A2) is involved in the genetics of AGA [68].

The AGA susceptibility genes were also investigated in autosomal regions, showing evidence for pathways other than the classical androgen pathway. A susceptibility locus was identified on chromosome 20p11 with a strong effect on the development of early-onset AGA and no obvious genetic connection to the androgen pathway [69]. A genome-wide association study suggested a new AGA susceptibility locus on chromosome 7p21.1, which is located intronically in the histone deacetylase 9 (HDAC9) gene [70]. HDAC9 was proposed as the third AGA susceptibility gene, as the major susceptibility genes are unequivocally confirmed in $\mathrm{AR}$ and EDA2R while the second strongest AGA susceptibility locus is on chromosome 20p11.7 [10, 62, 63, 67, 69, 71, 72]. The two AGA susceptibility loci on the $\mathrm{X}$ chromosome and chromosome 20 were confirmed in a large-scale meta-analysis [73]. Six new susceptibility loci also reached a genome-wide significance and a risk allele at $17 \mathrm{q} 21.31$ was unexpectedly identified on the gene intramembrane protease 5 , recently associated with Parkinson's disease.

As DPCs from balding scalp contain higher levels of AR than those from a non-balding scalp [18], the DPC proliferation and differentiation were studied for their possible role in the pathogenesis of AGA. The Wnt/ $\beta$-catenin pathway has been proposed as the main pathway involved [74-76], since AR interacts with $\beta$-catenin in an androgen dependent manner and their binding can inhibit Wnt signaling [72, 77]. Furthermore, some studies have shown a major role for Wnt signaling in regulating hair growth, suggesting a functional cross talk between AR and Wnt signaling pathways in target tissues [78-81]. Androgen treatment induced a significant decrease in the cytoplasmic/ total $\beta$-catenin protein ratio and inhibition of canonical Wnt in DPC [75]. These results suggest that androgens deregulate DPC-secreted factors involved in normal hair follicle stem cell differentiation via the inhibition of the canonical Wnt signaling pathway. Other candidate molecules for the pathogenesis of AGA are the p63 protein, an important regulator of hair follicle development, and CD34, a stem cell marker [82, 83]. The prevalence of $\mathrm{CD} 34+$ in hair follicles of the occipital scalp suggests that it might be key 
to hair follicle restoration and that its absence could contribute to AGA progression. Another inhibitor of hair growth in AGA was identified in the prostaglandin D2 [84]. However, a genome-wide association study failed to provide any genetic support for the role of prostaglandins in the early causative chain of events that lead to AGA [85].

Oxidative stress is the latest candidate for a role in AGA pathogenesis, as DPCs from male AGA patients underwent premature senescence in vitro compared with occipital DPCs in response to environmental stress [86-88]. Environmental oxygen significantly alters DPC morphology, migration, proliferation, senescence, and TGF- $\beta$ signaling [89]. Bald DPCs were significantly more sensitive to oxidative stress than were occipital DPCs and secreted higher levels of negative hair growth regulators, TGF- $\beta 1$, and $\beta 2$, in response to it.

\section{Treatment}

The choice of treatment for AGA depends on various factors including efficacy, practicability, risks, and costs. The aim is to prevent the miniaturization process and, if possible, to reverse it. Treatments include pharmacotherapy, surgery, and cosmetic aids. Despite the demand, there are only two FDA-approved medications to treat AGA: the potassium channel opener minoxidil, and the DHT synthesis inhibitor finasteride, both effective at controlling AGA with long-term daily use. However, they are costly, require lifelong treatment and may have side effects.

Medical therapy is most effective when started in the early phases of hair loss and patients may elect to be treated non-surgically only. Undoubtedly, medical therapy will play a central role as an adjunct to surgical treatment by preventing the loss of surrounding native hair and thus enhancing the overall esthetic result.

\section{Minoxidil}

Minoxidil was originally developed as an antihypertensive agent but attracted interest as a potential hair loss therapy, when patients receiving this drug developed generalized hypertrichosis [90]. This observation led to its topical formulation, which has become a first-line treatment of pattern hair loss. After application, minoxidil is converted to minoxidil sulfate, a potassium channel opener, which relaxes vascular smooth muscle and increases blood flow [91]. In vitro studies of hair growth have shown that hair cultures grown in the presence of minoxidil maintain morphology, whereas controls undergo kinking and necrosis [92]. Treatment results in increased hair weight with a less dramatic increase in hair count, suggesting that its therapeutic effect is primarily due to increasing the diameter of existing hairs. Topically applied minoxidil is currently available as an over-the-counter preparation in either a 2 or $5 \%$ solution or as a $5 \%$ foam. The response to treatment should be assessed ideally at the end of 6 months. Patients should be informed of telogen shedding, which is usually seen in the first 8 weeks of therapy [93]. A common side effect is contact dermatitis, which can initially be managed by switching to a $2 \%$ solution or to the foam preparation, which lacks propylene glycol [4]. Minoxidil treatment requires two daily application indefinitely to maintain results $[4,90,91]$.

\section{5a-reductase inhibitors (5aRi)}

The importance of DHT as an etiologic factor in male AGA is shown by the absence of this condition in men with a congenital $5 \alpha \mathrm{R} 2$ deficiency. Of the two $5 \mathrm{aR}$ isoenzymes in humans [94, 95], type I predominates in the liver and skin, including the scalp [96, 97, whereas type II is present in hair follicles [98], as well as the prostate and genitourinary tract [97]. Two 5 $\alpha \mathrm{R}$ inhibitors are used in AGA: finasteride, a $5 \alpha \mathrm{R} 2$ inhibitor, and dutasteride, which inhibits both $5 \alpha \mathrm{R} 1$ and $5 \alpha \mathrm{R} 2$. The FDA approved finasteride in 1997 at a dosage of $1 \mathrm{mg} /$ day for use in adult men with mildmoderate AGA. Oral dutasteride $0.5 \mathrm{mg}$ a day is another option, but there is a lack of studies comparing its efficacy to finasteride. Oral finasteride lowers serum, prostate and scalp DHT by approximately 60-70\% [99]. Recent studies also proved the efficacy of topical finasteride for AGA [100-104]. Studies in both humans and animals have shown that the combination of minoxidil $2 \%$ and finasteride $1 \mathrm{mg}$ is superior to monotherapies $[105,106]$.

The clinical efficacy of finasteride has been documented in well-controlled clinical trials that monitored men with AGA for up to 10 years [107]. Baldness progresses with discontinuation of finasteride as DHT levels return to pretreatment levels. The response to treatment should be assessed at 6 months, although in some men it may not become evident until 12 months. Finasteride is generally well tolerated with long-term daily use except for uncommon sexual adverse effects, including gynecomastia, reduced libido, erectile dysfunction, and ejaculatory disorders. A study by Overstreet et al. showed that finasteride $1 \mathrm{mg}$ daily for 48 weeks did not affect spermatogenesis or semen production in men aged 19-41 years [108]. The sexual symptoms of finasteride often diminish or resolve with continued treatment and generally reverse on treatment discontinuation. However, prolonged adverse effects on sexual function such as erectile dysfunction, diminished libido, depression, and decreased quality of life, are reported by a subset of men [109]. As the described symptoms seem to apply to 5ARis in general and manifest mainly after 5ARi withdrawal, this condition has been identified as a new medical problem, 5ARi Withdrawal Syndrome [110]. 
The genotype of those affected is currently unknown. Not all individuals are affected in the same way or to the same degree. Some patients present only weak side effects, while others suffer serious side effects, which include lifethreatening depression, severe muscle wasting, metabolic syndrome, osteoporosis and complete loss of all sexual function. These persistent side effects seem to relate to physiological and psychological functions which require androgens to function correctly. It has been hypothesized that the mechanism of these persistent hypogonadal symptoms and loss of androgenic action are due to a form of $5 \mathrm{ARi}$-induced androgen resistance as a consequence of AR overexpression due to the decreased androgen (DHT) availability. Since it shares a significant structural similarity with testosterone and DHT, finasteride may interfere with AR function, as proven in prostate cancer cell lines. Finasteride may act as an AR-ligand in addition to its role as a $5 \alpha \mathrm{R}$ inhibitor not only in the prostate, but also in hair follicles [111]. However, this antagonism, that could explain the persisted side effects of finasteride, has not been well characterized.

5ARi therapy may significantly reduce neurosteroid biosynthesis, inducing depressive symptoms [112]. Neuroactive steroids are produced in the central nervous system by transforming substrates from adrenal or gonadal steroids to active neurosteroids [113]. Neurosteroids and neuroactive steroids play an important role in memory enhancement and have sedative, hypnotic, anesthetic, anxiolytic, antistress, sleep modulating, anticonvulsant, and antidepressant properties. A reduced concentration of circulating neuroactive steroids during finasteride treatment is probably an important risk factor for depression.

\section{Conclusion}

Although the involvement of androgens in AGA is well established and a pathophysiology pathway has been proposed, further studies are needed to fully explain the genetic basis of AGA. Few studies have attempted to identify candidate genes for AGA because of its polygenic predisposition. Transgenerational manifestations may involve the $\mathrm{Y}$ chromosome or genes that are capable of parental imprinting. Once the underlying biological mechanisms have been established and our knowledge of the genetics AGA has increased, new targeted treatments may emerge.

Acknowledgments The authors wish to thank Marie-Hélène Hayles for her assistance in the English translation of the manuscript. This work was supported by a grant from the Italian Ministry of Education and Research (MIUR-PRIN) and the University of Rome "La Sapienza" Faculty of Medicine.
Authors contributions All authors have made substantial intellectual contribution to the work and approved it for publication.

Compliance with ethical standards

Conflict of interest The authors have no conflicts of interest.

\section{References}

1. J.B. Hamilton, Patterned loss of hair in man; types and incidence. Ann. N. Y. Acad. Sci. 53, 708-728 (1951)

2. L. Yip, S. Zaloumis, D. Irwin, G. Severi, J. Hopper, G. Giles, S. Harrap, R. Sinclair, J. Ellis, Gene-wide association study between the aromatase gene (CYP19A1) and female pattern hair loss. Br. J. Dermatol. 161, 289-294 (2009)

3. G. Severi, R. Sinclair, J.L. Hopper, D.R. English, M.R.E. McCredie, P. Boyle, G.G. Giles, Androgenetic alopecia in men aged 40-69 years: prevalence and risk factors. Br. J. Dermatol. 149, 1207-1213 (2003)

4. N. Otberg, A.M. Finner, J. Shapiro, Androgenetic alopecia. Endocrinol. Metab. Clin. N. Am. 36, 379-398 (2007)

5. R. Paus, G. Cotsarelis, The biology of hair follicles. N. Engl. J. Med. 341, 491-497 (1999)

6. C. Pierard-Franchimont, G.E. Pierard, Teloptosis, a turning point in hair shedding biorhythms. Dermatology 203, 115-117 (2001)

7. W.C. Chumlea, T. Rhodes, C.J. Girman, A. Johnson-Levonas, F. R.W. Lilly, R. Wu, S.S. Guo, Family history and risk of hair loss. Dermatology 209, 33-39 (2004)

8. D. Osborn, Inheritance of baldness. Various patterns due to heredity and sometimes present at birth-a sex-limited characterdominant in man-women not bald unless they inherit tendency from both parents. J. Hered. 7, 347-355 (1916)

9. W. Kuster, R. Happle, The inheritance of common baldness: two B or not two B ? J. Am. Acad. Dermatol. 11, 921-926 (1984)

10. E. Levy-Nissenbaum, M. Bar-Natan, M. Frydman, E. Pras, Confirmation of the association between male pattern baldness and the androgen receptor gene. Eur. J. Dermatol. 15, 339-340 (2005)

11. C.C. Zouboulis, K. Degitz, Androgen action on human skinfrom basic research to clinical significance. Exp. Dermatol. 13, 5-10 (2004)

12. K.S. Stenn, R. Paus, T. Dutton, B. Sarba, Glucocorticoid effect on hair growth initiation: a reconsideration. Skin Pharmacol. 6, 125-134 (1993)

13. D. Deplewski, R.L. Rosenfield, Role of hormones in pilosebaceous unit development. Endocr. Rev. 21, 363-392 (2000)

14. C. Roh, Q. Tao, S. Lyle, Dermal papilla-induced hair differentiation of adult epithelial stem cells from human skin. Physiol. Genom. 19, 207-217 (2004)

15. C. Blanpain, W.E. Lowry, A. Geoghegan, L. Polak, E. Fuchs, Self-renewal, multipotency, and the existence of two cell populations within an epithelial stem cell niche. Cell 118, 635-648 (2004)

16. V. Randall, in Hair and its Disorders: Biology, Pathology and Management, ed. By F. Camacho, V.A. Randall, P.V. The biology of androgenetic alopecia (Martin Dunitz, London, 2000), pp. $123-136$

17. A.J. Reynolds, R.F. Oliver, C.A. Jahoda, Dermal cell populations show variable competence in epidermal cell support: stimulatory effects of hair papilla cells. J. Cell Sci. 98(Pt 1), 75-83 (1991)

18. N.A. Hibberts, A.E. Howell, V.A. Randall, Balding hair follicle dermal papilla cells contain higher levels of androgen receptors 
than those from non-balding scalp. J. Endocrinol. 156, 59-65 (1998)

19. V.A. Botchkarev, J. Kishimoto, Molecular control of epithelialmesenchymal interactions during hair follicle cycling. in Journal of Investigative Dermatology Symposium Proceedings. pp 46-55 (2003)

20. V.A. Randall, M.J. Thornton, A.G. Messenger, Cultured dermal papilla cells from androgen-dependent human hair follicles (e.g. beard) contain more androgen receptors than those from nonbalding areas of scalp. J. Endocrinol. 133, 141-147 (1992)

21. S. Itami, S. Kurata, S. Takayasu, Androgen induction of follicular epithelial cell growth is mediated via insulin-like growth factor-I from dermal papilla cells. Biochem. Biophys. Res. Commun. 212, 988-994 (1995)

22. S. Inui, Y. Fukuzato, T. Nakajima, K. Yoshikawa, S. Itami, Identification of androgen-inducible TGF-betal derived from dermal papilla cells as a key mediator in Androgenetic alopecia. J Investig. Dermatol. Symp. Proc. 8, 69-71 (2003)

23. M. Philpott, in Hair and its Disorders: Biology, Research and Management. ed. By F. Camacho, IV. Randal, V. Price. The roles of growth factors in hair follicles: investigations using cultured hair follicles (Martin Dunitz, London, 2001) pp. 103113

24. R.D. Sinclair, Male androgenetic alopecia (Part II). J. Men's Health Gend. 2, 38-44 (2005)

25. S. Inui, Y. Fukuzato, T. Nakajima, K. Yoshikawa, S. Itami, Androgen-inducible TGF-beta1 from balding dermal papilla cells inhibits epithelial cell growth: a clue to understand paradoxical effects of androgen on human hair growth. FASEB J. 16, 1967-1969 (2002)

26. S. Inui, S. Itami, Molecular basis of androgenetic alopecia: from androgen to paracrine mediators through dermal papilla. J. Dermatol. Sci. 61, 1-6 (2011)

27. T. Hibino, T. Nishiyama, Role of TGF-beta2 in the human hair cycle. J. Dermatol. Sci. 35, 9-18 (2004)

28. M.H. Kwack, Y.K. Sung, E.J. Chung, S.U. Im, J.S. Ahn, M.K. Kim, J.C. Kim, Dihydrotestosterone-inducible dickkopf 1 from balding dermal papilla cells causes apoptosis in follicular keratinocytes. J. Invest. Dermatol. 128, 262-269 (2008)

29. M.H. Kwack, J.S. Ahn, M.K. Kim, J.C. Kim, Y.K. Sung, Dihydrotestosterone-inducible IL-6 inhibits elongation of human hair shafts by suppressing matrix cell proliferation and promotes regression of hair follicles in mice. J. Invest. Dermatol. 132, 43-49 (2012)

30. V. Poor, S. Juricskay, E. Telegdy, Urinary steroids in men with male-pattern alopecia. J. Biochem. Biophys. Methods 53, 123-130 (2002)

31. C.C. Zouboulis, The human skin as a hormone target and an endocrine gland. Hormones 3, 9-26 (2004)

32. M. Fritsch, C.E. Orfanos, C.C. Zouboulis, Sebocytes are the key regulators of androgen homeostasis in human skin. J. Invest. Dermatol. 116, 793-800 (2001)

33. L. Di Luigi, F. Romanelli, A. Lenzi, Androgenic-anabolic steroids abuse in males. J. Endocrinol. Invest. 28, 81-84 (2005)

34. S. Inui, S. Itami, Androgen actions on the human hair follicle: perspectives. Exp. Dermatol. 22, 168-171 (2013)

35. R. Hoffmann, Enzymology of the hair follicle. Eur. J. Dermatol. 11, 296-300 (2001)

36. U. Hoppe, P.-M. Holterhus, L. Wunsch, D. Jocham, T. Drechsler, S. Thiele, C. Marschke, O. Hiort, Tissue-specific transcription profiles of sex steroid biosynthesis enzymes and the androgen receptor. J. Mol. Med. 84, 651-659 (2006)

37. D. Thiboutot, P. Martin, L. Volikos, K. Gilliland, Oxidative activity of the type 2 isozyme of 17beta-hydroxysteroid dehydrogenase (17beta-HSD) predominates in human sebaceous glands. J. Invest. Dermatol. 111, 390-395 (1998)
38. S. Takayasu, Metabolism and action of androgen in the skin. Int. J. Dermatol. 18, 681-692 (1979)

39. D.W. Russell, D.M. Berman, J.T. Bryant, K.M. Cala, D.L. Davis, C.P. Landrum, J.S. Prihoda, R.I. Silver, A.E. Thigpen, W. C. Wigley, The molecular genetics of steroid 5 alpha-reductases. Recent Prog. Horm. Res. 49, 275-284 (1994)

40. S. Nakanishi, I. Adachi, K. Takayasu. in Hair Research for the Next Millennium. ed. By D. Neste. Expression of androgen receptor, type I and type II 5a-reductase in human dermal papilla cellse (VREPB, Amsterdam, 1996) pp 333-337

41. Y. Asada, T. Sonoda, M. Ojiro, S. Kurata, T. Sato, T. Ezaki, S. Takayasu, 5 alpha-reductase type 2 is constitutively expressed in the dermal papilla and connective tissue sheath of the hair follicle in vivo but not during culture in vitro. J. Clin. Endocrinol. Metab. 86, 2875-2880 (2001)

42. M.E. Sawaya, V.H. Price, Different levels of 5alpha-reductase type I and II, aromatase, and androgen receptor in hair follicles of women and men with androgenetic alopecia. J. Invest. Dermatol. 109, 296-300 (1997)

43. M.E. Sawaya, N.S. Penneys, Immunohistochemical distribution of aromatase and 3B-hydroxysteroid dehydrogenase in human hair follicle and sebaceous gland. J. Cutan. Pathol. 19, 309-314 (1992)

44. U. Ohnemus, M. Uenalan, J. Inzunza, J.-A. Gustafsson, R. Paus, The hair follicle as an estrogen target and source. Endocr. Rev. 27, 677-706 (2006)

45. V.A. Randall, Role of $5 \alpha$-reductase in health and disease, Baillière's Clinical Endocrinology and Metabolism. 8(2), 405-431 (1994). doi:10.1016/S0950-351X(05)80259-9.

46. D. Gianfrilli, S. Pierotti, R. Pofi, C. Leonardo, M. Ciccariello, F. Barbagallo, Sex steroid metabolism in benign and malignant intact prostate biopsies: individual profiling of prostate intracrinology. Biomed. Res. Int. 2014, 464869 (2014)

47. M.J. McPhaul, Androgen receptor mutations and androgen insensitivity. Mol. Cell. Endocrinol. 198, 61-67 (2002)

48. J.D. Wilson, J.E. Griffin, D.W. Russell, Steroid 5 alphareductase 2 deficiency. Endocr. Rev. 14, 577-593 (1993)

49. T. Liang, S. Hoyer, R. Yu, K. Soltani, A.L. Lorincz, R.A. Hiipakka, S. Liao, Immunocytochemical localization of androgen receptors in human skin using monoclonal antibodies against the androgen receptor. J. Invest. Dermatol. 100, 663-666 (1993)

50. T. Tadokoro, S. Itami, K. Hosokawa, H. Terashi, S. Takayasu, Human genital melanocytes as androgen target cells. J. Invest. Dermatol. 109, 513-517 (1997)

51. S. Itami, S. Kurata, T. Sonoda, S. Takayasu, Interaction between dermal papilla cells and follicular epithelial cells in vitro: effect of androgen. Br. J. Dermatol. 132, 527-532 (1995)

52. S. Inui, S. Itami, H.J. Pan, C. Chang, Lack of androgen receptor transcriptional activity in human keratinocytes. J. Dermatol. Sci. 23, 87-92 (2000)

53. J.E. Cobb, N.C. Wong, L.W. Yip, J. Martinick, R. Bosnich, R.D. Sinclair, J.M. Craig, R. Saffery, S.B. Harrap, J.A. Ellis, Evidence of increased DNA methylation of the androgen receptor gene in occipital hair follicles from men with androgenetic alopecia. $\mathrm{Br}$. J. Dermatol. 165, 210-213 (2011)

54. N. Fujimoto, S. Yeh, H.Y. Kang, S. Inui, H.C. Chang, A. Mizokami, C. Chang, Cloning and characterization of androgen receptor coactivator, ARA55, in human prostate. J. Biol. Chem. 274, 8316-8321 (1999)

55. S. Inui, Y. Fukuzato, T. Nakajima, S. Kurata, S. Itami, Androgen receptor co-activator Hic-5/ARA55 as a molecular regulator of androgen sensitivity in dermal papilla cells of human hair follicles. J. Invest. Dermatol. 127, 2302-2306 (2007)

56. S. Itami, S. Kurata, S. Takayasu, 5 Alpha-reductase activity in cultured human dermal papilla cells from beard compared with reticular dermal fibroblasts. J. Invest. Dermatol. 94, 150-152 (1990) 
57. S. Itami, S. Kurata, T. Sonoda, S. Takayasu, Characterization of 5 alpha-reductase in cultured human dermal papilla cells from beard and occipital scalp hair. J. Invest. Dermatol. 96, 57-60 (1991)

58. P. Lee, C.-C. Zhu, N.S. Sadick, A.H. Diwan, P.S. Zhang, J.S. Liu, V.G. Prieto, Expression of androgen receptor coactivator ARA70/ELE1 in androgenic alopecia. J. Cutan. Pathol. 32, 567-571 (2005)

59. M.E. Sawaya, A.R. Shalita, Androgen receptor polymorphisms (CAG repeat lengths) in androgenetic alopecia, hirsutism, and acne. J. Cutan. Med. Surg. 3, 9-15 (1998)

60. A.M. Hillmer, S. Hanneken, S. Ritzmann, T. Becker, J. Freudenberg, F.F. Brockschmidt, A. Flaquer, Y. Freudenberg-Hua, R. A. Jamra, C. Metzen, U. Heyn, N. Schweiger, R.C. Betz, B. Blaumeiser, J. Hampe, S. Schreiber, T.G. Schulze, H.C. Hennies, J. Schumacher, P. Propping, T. Ruzicka, S. Cichon, T.F. Wienker, R. Kruse, M.M. Nothen, Genetic variation in the human androgen receptor gene is the major determinant of common early-onset androgenetic alopecia. Am. J. Hum. Genet. 77, 140-148 (2005)

61. J.A. Ellis, M. Stebbing, S.B. Harrap, Polymorphism of the androgen receptor gene is associated with male pattern baldness. J. Invest. Dermatol. 116, 452-455 (2001)

62. J.A. Ellis, K.J. Scurrah, J.E. Cobb, S.G. Zaloumis, A.E. Duncan, S.B. Harrap, Baldness and the androgen receptor: the AR polyglycine repeat polymorphism does not confer susceptibility to androgenetic alopecia. Hum. Genet. 121, 451-457 (2007)

63. V.M. Hayes, G. Severi, Sa Eggleton, E.J.D. Padilla, M.C. Southey, R.L. Sutherland, J.L. Hopper, G.G. Giles, Short communication the E211 G > a androgen receptor polymorphism is associated with a decreased risk of metastatic prostate cancer and androgenetic alopecia. Cancer Epidemiol. 14, 993-996 (2005)

64. J.E. Cobb, S.J. White, S.B. Harrap, J.A. Ellis, Androgen receptor copy number variation and androgenetic alopecia: a case-control study. PLoS One 4, e5081 (2009)

65. D.A. Prodi, N. Pirastu, G. Maninchedda, A. Sassu, A. Picciau, M.A. Palmas, A. Mossa, I. Persico, M. Adamo, A. Angius, M. Pirastu, EDA2R is associated with androgenetic alopecia. J. Invest. Dermatol. 128, 2268-2270 (2008)

66. A.M. Hillmer, J. Freudenberg, S. Myles, S. Herms, K. Tang, D. A. Hughes, F.F. Brockschmidt, Y. Ruan, M. Stoneking, M.M. Nöthen, Recent positive selection of a human androgen receptor/ ectodysplasin A2 receptor haplotype and its relationship to male pattern baldness. Hum. Genet. 126, 255 (2009)

67. F.F. Brockschmidt, A.M. Hillmer, S. Eigelshoven, S. Hanneken, S. Heilmann, S. Barth, C. Herold, T. Becker, R. Kruse, M.M. Nöthen, Fine mapping of the human AR/EDA2R locus in androgenetic alopecia. Br. J. Dermatol. 162, 899-903 (2010)

68. J.A. Ellis, M. Stebbing, S.B. Harrap, Genetic analysis of male pattern baldness and the 5alpha-reductase genes. J. Invest. Dermatol. 110, 849-853 (1998)

69. J.B. Richards, X. Yuan, F. Geller, D. Waterworth, V. Bataille, D. Glass, K. Song, G. Waeber, P. Vollenweider, K.K.H. Aben, L.A. Kiemeney, B. Walters, N. Soranzo, U. Thorsteinsdottir, A. Kong, T. Rafnar, P. Deloukas, P. Sulem, H. Stefansson, K. Stefansson, T.D. Spector, V. Mooser, Male-pattern baldness susceptibility locus at 20p11. Nat. Genet. 40, 1282-1284 (2008)

70. F.F. Brockschmidt, S. Heilmann, J.A. Ellis, S. Eigelshoven, S. Hanneken, C. Herold, S. Moebus, M.A. Alblas, B. Lippke, N. Kluck, L. Priebe, F.A. Degenhardt, R.A. Jamra, C. Meesters, K. H. Jöckel, R. Erbel, S. Harrap, J. Schumacher, H. Fröhlich, R. Kruse, A.M. Hillmer, T. Becker, M.M. Nöthen, Susceptibility variants on chromosome 7p21.1 suggest HDAC9 as a new candidate gene for male-pattern baldness. Br. J. Dermatol. 165, 1293-1302 (2011)

71. A.M. Hillmer, F.F. Brockschmidt, S. Hanneken, S. Eigelshoven, M. Steffens, A. Flaquer, S. Herms, T. Becker, A.-K. Kortüm, D.
R. Nyholt, Z.Z. Zhao, G.W. Montgomery, N.G. Martin, T.W. Mühleisen, M.A. Alblas, S. Moebus, K.-H. Jöckel, M. BröckerPreuss, R. Erbel, R. Reinartz, R.C. Betz, S. Cichon, P. Propping, M.P. Baur, T.F. Wienker, R. Kruse, M.M. Nöthen, Susceptibility variants for male-pattern baldness on chromosome 20p11. Nat. Genet. 40, 1279-1281 (2008)

72. D.R. Chesire, W.B. Isaacs, Ligand-dependent inhibition of betacatenin/TCF signaling by androgen receptor. Oncogene 21, 8453-8469 (2002)

73. R. Li, F.F. Brockschmidt, A.K. Kiefer, H. Stefansson, D.R. Nyholt, K. Song, S.H. Vermeulen, S. Kanoni, D. Glass, S.E. Medland, M. Dimitriou, D. Waterworth, J.Y. Tung, F. Geller, S. Heilmann, A.M. Hillmer, V. Bataille, S. Eigelshoven, S. Hanneken, S. Moebus, C. Herold, M. den Heijer, G.W. Montgomery, P. Deloukas, N. Eriksson, A.C. Heath, T. Becker, P. Sulem, M. Mangino, P. Vollenweider, T.D. Spector, G. Dedoussis, N.G. Martin, L.A. Kiemeney, V. Mooser, K. Stefansson, D.A. Hinds, M.M. Nöthen, J.B. Richards, Six novel susceptibility loci for early-onset androgenetic alopecia and their unexpected association with common diseases. PLoS Genet. 8, e1002746 (2012)

74. T. Kitagawa, K.I. Matsuda, S. Inui, H. Takenaka, N. Katoh, S. Itami, S. Kishimoto, M. Kawata, Keratinocyte growth inhibition through the modification of wnt signaling by androgen in balding dermal papilla cells. J. Clin. Endocrinol. Metab. 94, 1288-1294 (2009)

75. G.J. Leirõs, A.I. Attorresi, M.E. Balañá, Hair follicle stem cell differentiation is inhibited through cross-talk between $\mathrm{Wnt} / \beta$ catenin and androgen signalling in dermal papilla cells from patients with androgenetic alopecia. Br. J. Dermatol. 166, 1035-1042 (2012)

76. J.S. Crabtree, E.J. Kilbourne, B.J. Peano, S. Chippari, T. Kenney, C. McNally, W. Wang, H.A. Harris, R.C. Winneker, S. Nagpal, C.C. Thompson, A mouse model of androgenetic alopecia. Endocrinology 151, 2373-2380 (2010)

77. F. Yang, X. Li, M. Sharma, C.Y. Sasaki, D.L. Longo, B. Lim, Z. Sun, Linking beta-catenin to androgen-signaling pathway. J. Biol. Chem. 277, 11336-11344 (2002)

78. J. Kishimoto, R.E. Burgeson, B.A. Morgan, Wnt signaling maintains the hair-inducing activity of the dermal papilla. Genes Dev. 14, 1181-1185 (2000)

79. C. Lo Celso, D.M. Prowse, F.M. Watt, Transient activation of betacatenin signalling in adult mouse epidermis is sufficient to induce new hair follicles but continuous activation is required to maintain hair follicle tumours. Development 131, 1787-1799 (2004)

80. D. Van Mater, F.T. Kolligs, A.A. Dlugosz, E.R. Fearon, Transient activation of beta -catenin signaling in cutaneous keratinocytes is sufficient to trigger the active growth phase of the hair cycle in mice. Genes Dev. 17, 1219-1224 (2003)

81. T. Andl, S.T. Reddy, T. Gaddapara, S.E. Millar, WNT signals are required for the initiation of hair follicle development. Dev. Cell 2, 643-653 (2002)

82. A.A. Mills, B. Zheng, X.J. Wang, H. Vogel, D.R. Roop, A. Bradley, p63 is a p53 homologue required for limb and epidermal morphogenesis. Nature 398, 708-713 (1999)

83. M. Sosnova, M. Bradl, J.V. Forrester, CD34+ corneal stromal cells are bone marrow-derived and express hemopoietic stem cell markers. Stem Cells 23, 507-515 (2005)

84. L.A. Garza, Y. Liu, Z. Yang, B. Alagesan, J.A. Lawson, S.M. Norberg, D.E. Loy, T. Zhao, H.B. Blatt, D.C. Stanton, L. Carrasco, G. Ahluwalia, S.M. Fischer, G.A. FitzGerald, G. Cotsarelis, Prostaglandin D2 inhibits hair growth and is elevated in bald scalp of men with androgenetic alopecia 4, 126ra34 (2012).

85. S. Heilmann, D.R. Nyholt, F.F. Brockschmidt, A.M. Hillmer, C. Herold, T. Becker, N.G. Martin, M.M. Nöthen, No genetic support for a contribution of prostaglandins to the aetiology of androgenetic alopecia. Br. J. Dermatol. 169, 222-224 (2013) 
86. A.W. Bahta, N. Farjo, B. Farjo, M.P. Philpott, Premature senescence of balding dermal papilla cells in vitro is associated with p16(INK4a) expression. J. Invest. Dermatol. 128, 1088-1094 (2008)

87. Q.M. Chen, Replicative senescence and oxidant-induced premature senescence. Beyond the control of cell cycle checkpoints. Ann. N. Y. Acad. Sci. 908, 111-125 (2000)

88. J.H. Upton, R.F. Hannen, A.W. Bahta, N. Farjo, B. Farjo, M.P. Philpott, Oxidative stress-associated senescence in dermal papilla cells of men with androgenetic alopecia. J. Investig. Dermatol. Adv. Online Publ. 135, 1244-1252 (2015)

89. M. Bienova, R. Kucerova, M. Fiuraskova, M. Hajduch, Z. Kolar, Androgenetic alopecia and current methods of treatment. Acta. Dermatovenerol. Alp. Pannonica Adriat. 14, 5-8 (2005)

90. H.S. Shin, C.H. Won, S.H. Lee, O.S. Kwon, K.H. Kim, H.C. Eun, Efficacy of $5 \%$ minoxidil versus combined $5 \%$ minoxidil and $0.01 \%$ tretinoin for male pattern hair loss: a randomized, double-blind, comparative clinical trial. Am. J. Clin. Dermatol. 8, 285-290 (2007)

91. A.E. Buhl, D.J. Waldon, T.T. Kawabe, J.M. Holland, Minoxidil stimulates mouse vibrissae follicles in organ culture. J. Invest. Dermatol. 92, 315-320 (1989)

92. A. Blumeyer, A. Tosti, A. Messenger, P. Reygagne, V. Del Marmol, P.I. Spuls, M. Trakatelli, A. Finner, F. Kiesewetter, R. Trüeb, B. Rzany, U. Blume-Peytavi, Evidence-based (S3) guideline for the treatment of androgenetic alopecia in women and in men. JDDG 9, S1-S57 (2011)

93. E.P. Jenkins, S. Andersson, J. Imperato-McGinley, J.D. Wilson, D.W. Russell, Genetic and pharmacological evidence for more than one human steroid 5 alpha-reductase. J. Clin. Invest. 89, 293-300 (1992)

94. D.W. Russell, J.D. Wilson, Steroid 5 alpha-reductase: two genes/ two enzymes. Annu. Rev. Biochem. 63, 25-61 (1994)

95. G. Harris, B. Azzolina, W. Baginsky, G. Cimis, G.H. Rasmusson, R.L. Tolman, C.R. Raetz, K. Ellsworth, Identification and selective inhibition of an isozyme of steroid 5 alpha-reductase in human scalp. Proc. Natl Acad. Sci. USA 89, 10787-10791 (1992)

96. A.E. Thigpen, R.I. Silver, J.M. Guileyardo, M.L. Casey, J.D. McConnell, D.W. Russell, Tissue distribution and ontogeny of steroid 5 alpha-reductase isozyme expression. J. Clin. Invest. 92, 903-910 (1993)

97. E. Bayne, J. Flanagan, B. Azzolina, R. Einstein, J. Mumford, B. Avala, D. Chang, I. Thiboutot, I. Singer, G. Harris, Immunolocalization of type 2 5a-reductase in human hair follicles [abstract]. in 1997 Annual Meeting Society for Investigative Dermatology. p. 651 (1997)

98. L. Drake, M. Hordinsky, V. Fiedler, J. Swinehart, W.P. Unger, P.C. Cotterill, D.M. Thiboutot, N. Lowe, C. Jacobson, D. Whiting, S. Stieglitz, S.J. Kraus, E.I. Griffin, D. Weiss, P. Carrington, C. Gencheff, G.W. Cole, D.M. Pariser, E.S. Epstein, W. Tanaka, A. Dallob, K. Vandormael, L. Geissler, J. Waldstreicher, The effects of finasteride on scalp skin and serum androgen levels in men with androgenetic alopecia. J. Am. Acad. Dermatol. 41, 550-554 (1999)

99. M. Caserini, M. Radicioni, C. Leuratti, E. Terragni, M. Iorizzo, R. Palmieri, Effects of a novel finasteride $0.25 \%$ topical solution on scalp and serum dihydrotestosterone in healthy men with androgenetic alopecia. Int. J. Clin. Pharmacol. Ther. 54, 19-27 (2016)

100. M. Caserini, M. Radicioni, C. Leuratti, O. Annoni, R. Palmieri, A novel finasteride $0.25 \%$ topical solution for androgenetic alopecia: pharmacokinetics and effects on plasma androgen levels in healthy male volunteers. Int. J. Clin. Pharmacol. Ther. 52, 842-849 (2014)

101. B.S. Chandrashekar, T. Nandhini, V. Vasanth, R. Sriram, S. Navale, Topical minoxidil fortified with finasteride: An account of maintenance of hair density after replacing oral finasteride. Indian Dermatol. Online J. 6, 17-20 (2015)

102. Z. Hajheydari, J. Akbari, M. Saeedi, L. Shokoohi, Comparing the therapeutic effects of finasteride gel and tablet in treatment of the androgenetic alopecia. Indian J. Dermatol. Venereol. Leprol. 75, 47-51 (2009)

103. C. Tanglertsampan, Efficacy and safety of $3 \%$ minoxidil versus combined $3 \%$ minoxidil / $0.1 \%$ finasteride in male pattern hair loss: a randomized, double-blind, comparative study. J. Med. Assoc. Thail. 95, 1312-1316 (2012)

104. S. Khandpur, M. Suman, B.S. Reddy, Comparative efficacy of various treatment regimens for androgenetic alopecia in men. J. Dermatol. 29, 489-498 (2002)

105. A.R. Diani, M.J. Mulholland, K.L. Shull, M.F. Kubicek, G.A. Johnson, H.J. Schostarez, M.N. Brunden, A.E. Buhl, Hair growth effects of oral administration of finasteride, a steroid $5 \alpha$ reductase inhibitor, alone and in combination with topical minoxidil in the balding stumptail macaque. J. Clin. Endocrinol. Metab. 74, 345-350 (1992)

106. A. Rossi, C. Cantisani, M. Scarno, A. Trucchia, M.C. Fortuna, S. Calvieri, Finasteride, $1 \mathrm{mg}$ daily administration on male androgenetic alopecia in different age groups: 10-year follow-up. Dermatol. Ther. 24, 455-461 (2011)

107. J.W. Overstreet, V.L. Fuh, J. Gould, S.S. Howards, M.M. Lieber, W. Hellstrom, S. Shapiro, P. Carroll, R.S. Corfman, S. Petrou, R. Lewis, P. Toth, T. Shown, J. Roy, J.P. Jarow, J. Bonilla, C.A. Jacobsen, D.Z. Wang, K.D. Kaufman, Chronic treatment with finasteride daily does not affect spermatogenesis or semen production in young men. J. Urol. 162, 1295-1300 (1999)

108. A.M. Traish, J. Hassani, A.T. Guay, M. Zitzmann, M.L. Hansen, Adverse side effects of $5 \alpha$-reductase inhibitors therapy: persistent diminished libido and erectile dysfunction and depression in a subset of patients. J. Sex. Med. 8, 872-884 (2011)

109. M.S. Irwig, S. Kolukula. Persistent sexual side effects of finasteride for male pattern hair loss. J. Sex. Med. 8, 1747-1753 (2011)

110. Y. Wu, R.R. Chhipa, H. Zhang, C. Ip, The antiandrogenic effect of finasteride against a mutant androgen receptor. Cancer Biol. Ther. 11, 902-909 (2011)

111. D.A. Finn, S.L. Long, M.A. Tanchuck, J.C. Crabbe, Interaction of chronic ethanol exposure and finasteride: sex and strain differences. Pharmacol. Biochem. Behav. 78, 435-443 (2004)

112. B. Stoffel-Wagner, Neurosteroid biosynthesis in the human brain and its clinical implications. Ann. N. Y. Acad. Sci. 1007, 64-78 (2003)

113. R. Rupprecht, F. Holsboer, Neuroactive steroids: mechanisms of action and neuropsychopharmacological perspectives. Trends Neurosci. 22, 410-416 (1999) 